chọn nhiều nhất để khám lần đầu khi có vấn đề sức khỏe $(37,6 \%)$. Bệnh viện trung ương và bệnh viện tỉnh là nơi được chọn để điều trị nội trú nhiều nhất với $36,4 \%$ và $31,8 \%$. Các đối tượng điều trị ngoại trú tại trung tâm y tế huyện nhiêu nhất $(34,2 \%)$ và bệnh viện trung ương (32,9\%). Có 95,5\% đối tượng sử dụng bảo hiểm y tế khi điều trị nội trú nhưng chỉ có $50 \%$ đối tượng sử dụng bảo hiểm y tế khi điều trị ngoại trú.

Một số yếu tố liên quan đến việc sử dụng dịch vụ y tế là: nữ giới có xu hướng sử dụng dịch vụ hơn nam giới 1,9 lần $(p<0,05)$; người sống với vợ/chồng/người yêu có khả năng sử dụng dịch vụ cao hơn 2,19 lần so với người sống độc thân $(p<0,05)$ và những người mắc bệnh trong 3 tháng qua sử dụng dịch vụ gấp 4,09 lần so với người không có vấn đề sức khỏe $(p<0,001)$; những người thường đến $B V$ huyện/Trạm y tế ít hơn 0,48 lần và người thường tự mua thuốc cũng ít hơn 0,34 lần so với người thường đến $B V$ tuyến TU'/tỉnh $(p<0,05)$.

Lời cảm ơn. Để hoàn thành nghiên cứu này, nhóm nghiên cứu xin gửi lời cảm ơn sâu sắc đến Phòng Đào tạo-Nghiên cứu khoa học và Hợp tác quốc tế và các Thây Cô thuộc Viện đào tạo Y học dự phòng và $Y$ tế công cộng đã phối hợp thực hiện và giúp đỡ trong quá trình triển khai và thu thập số liệu nghiên cứu. Tác giả Nguyễn Thị Thu Hường được tài trợ bởi nhà tài trợ thuộc Tập đoàn Vingroup và hỗ trợ bởi chương trình học bổng đào tạo thạc sĩ, tiến sĩ trong nước của Quỹ
Đổi mới sáng tạo Vingroup (VINIF), Viện Nghiên cứu Dữ liệu lớn (VinBigdata), mã số VINIF. 2020.TS.30. Nhóm tác giả tham gia nghiên cứu cam kết không có xung đột lợi ích từ kết quả nghiên cứu.

\section{TÀI LIỆU THAM KHẢO}

1. Tổng cục thống kê (2018), Kết quả khảo sát mức sống dân cư Việt Nam 2018,

2. Tổng cực thống kề (2012), tổng Điều tra $Y$ tế, mức sống dân cứ, văn hóa, thể thao, trật tự an toàn xã hội và môi trường 2012.

3. Trương Việt Dũng, Nguyễn Thanh Tâm, and Gill Tipping Chất lượng các dịch vụ y tế công cộng và những quyết định của gia đình vê chăm sóc sức khỏe tai 4 xã ở Quảng Ninh, Hà Nôi.

4. Mai Thị Thanh Xuân (2011). Sử dụng dịch vụ y tế của người nghèo ở Hà Nội. Tạp Chí Khoa Học ĐHQGHN, 27(27), 256-264.

5. Sở Y Tế'Thành Phố Hồ Chí Minh Báo cáo hoạt động quản lý khám chữa bệnh tại các cơ sở y tế tại thành phố Hồ Chí Minh năm 2019,

6. Thuong N.T.T., Huy T.Q., Tai D.A., et al. (2020). Impact of Health Insurance on Health Care Utilisation and Out-of-Pocket Health Expenditure in Vietnam. BioMed Res Int, 2020, 9065287.

7. Nguyen H.T.L., Nakamura K., Seino K., et al. (2017). Association Between a Wider Availability of Health Information and Health Care Utilization in Vietnam: Cross-Sectional Study. J Med Internet Res, 19(12), e405.

8. Trần Xuân Bách, Nguyễn Long Hoàng, Nông Minh Vương, et al. (2016). Health status and health service utilization in remote and mountainous areas in Vietnam. Health Qual Life Outcomes, 14(1), 85.

\title{
CÁC YẾU Tố TIÊN LƯợNG CAI MÁY THÀNH CÔNG CỦA PHƯƠ'NG THỨC THÔNG KHÍ THÍCH ỨNG Ở BỆNH NHÂN ĐợT CẤP BÊ̂NH PHỔI TẮC NGHẼN MẠN TÍNH
}

\section{TÓM TẮT}

Mục tiêu: Nhận xét các yếu tố tiên lượng cai máy thành công của phương thức thông khí thích ứng (AVM) cho bệnh nhân đợt cấp bệnh phổi tắc nghẽn man tính (COPD). Phướng pháp: Nghiên cứu tiến cứu trên 25 bệnh nhân đợt câp COPD nhập trung tâm Cấp cứu bệnh viện Bạch Mai thông khí xâm nhập đủ

*Bệnh viện Bạch Mai,

**Bệnh viện đa khoa tinh Phú Tho

Chịu trách nhiệm chính: Đỗ Ngọc Sơn

Email: sonngocdo@gmail.com

Ngày nhận bài: 2.8.2021

Ngày phản biện khoa học: 29.9.2021

Ngày duyệt băi: 7.10.2021

\section{Đỗ Ngọc Sơn*, Nguyễn Đức Lịch**}

điều kiện cai thở máy từ tháng 09/2020 đến tháng 9/2021. Các thông số theo dôi chính như tuổi, giới, các chi số khí máu: $\mathrm{pH}_{1}, \mathrm{PaCO}_{2}, \mathrm{PaO}_{2}, \mathrm{HCO}_{3}$, $\mathrm{PaO}_{2} / \mathrm{FiO}_{2}$, lactat các thông số lâm sàng: mạch, huyết áp, nhịp thở, SpO2 được thu thập tại các thời điêm: nhập viện, bắt đâu cai máy thở bằng AVM, sau thở AVMM 30 phút, sau 60 phút, sau 120 phút, trước rút ông nội khí quản hoặc trước khi chuyên lại thông khí kiêm soát và sau rút ống nội khí quản. Bênh nhân được đánh giá thành công khi không phải đặt lại nội khí quản sau 48 giờ. Kết quả: Nghiên cứu trển 25 bệnh nhân (tuổi trung bình 74,04 $\pm 9,92$ tuổi; $8 \%$ nữ giới) cho kêt quả có 21 (84\%) bênh nhân rút ống nội khí quản thành công. Tại thời điểm nhập viện nhóm thành công có điểm SOFA $(4,82 \pm 2,1)$ và điểm $\operatorname{APACHE}$ II $(16,24 \pm 4,44)$, thấp hơn so với nhóm thất 
bại có điểm SOFA( $9 \pm 1,92)$, điểm APACHE II $(21,2 \pm 2,99)$ với $p<0,05$. Diễn biến về nhịp tim, nhịp thở, pH, PaCO2, lactat của nhóm thành công ổn định trong quá trình cai thở máy và ở nhóm thất bại nhịp tim, nhịp thở, $\mathrm{PaCO} 2$ tăng dân, pH giảm dần từ thời điểm 60 phút sau cai thở máy, khác biệt rõ nhất tại thời điểm trước khi rút nội khí quản hoăc trước khi chuyển lại thông khí kiểm soát với $p<0,05$. Kết luận: Thang điểm APACHE II, SOFA tại thời điểm nhập viện có khả năng dự báo kết quả rút ống nội khí quản thành công. Theo dõi diễn biến trong quá trình cai máy về nhịp tim, nhịp thở, $\mathrm{pH}, \mathrm{PaCO} 2$, lactat có thể tiên lương cai máy thở thành công áp dung phương thức thông khí thích ứng cho bệnh nhân đợt cấp COPD.

Tư khóa: Thông khí nhẩn tạo xâm nhâp, AVM đợt cấp bệnh phổi tắc nghẽn mạn tính, cai thở máy.

\section{SUMMARY}

PREDICTORS OF SUCCESSFUL WEANING BY THE ADAPTIVE VENTILATION MODE ON PATIENTS WITH THE EXACERBATION OF CHRONIC OBSTRUCTIVE PULMONARY DISEASE

Objective: To identity predictive factors for successful weaning by the adaptive ventilation mode (AVM) on patients with the exacerbation of chronic obstructive pulmonary disease (COPD). Methods: A prospective study was carried out, on 25 invasive ventilated patients with COPD exacerbations admitted to the Emergency Department of Bach Mai Hospital from September 2020 to August 2021. The main variables such as age, sex, blood gas indices: $\mathrm{pH}$, $\mathrm{PaCO} 2, \mathrm{PaO} 2, \mathrm{HCO} 3, \mathrm{PaO} 2 / \mathrm{FiO} 2$ ratio, lactate, vital signs parameters: heart rate, blood pressure, respiratory rate, $\mathrm{SpO} 2$ were collected at the timelines: admission, 30 minutes, 60 minutes, 120 minutes after AVM, before extubation and after extubation. Patients were considered successfully weaned if they were not be re-intubated after 48 hours. Results: Among 25 patients (mean age $74.04 \pm 9.92$ years; $8 \%$ women) there were $21(84 \%)$ patients with successful tracheal extubation. On admission, the successful group had SOFA score $(4.82 \pm 2.1)$ and APACHE II score $(16.24 \pm 4.44)$, lower than that of the failure group $9 \pm 1.92,21.2 \pm 2.99$, respectively with $p<0.05$. The heart rate, respiratory rate, $\mathrm{pH}, \mathrm{PaCO} 2$, lactate of the successful group was stable during weaning meanwhile the heart rate, respiratory rate gradually increased, $\mathrm{pH}$ gradually decreased in the 60 minutes after weaning, the most significant difference was before extubation or before switching back to continuous mandatory ventilation with $\mathrm{p}<0,05$. Conclusion: APACHE II, SOFA scores on admission are able to predict the successful extubation. Monitoring the heart rate, respiratory rate, $\mathrm{pH}, \mathrm{PaCO} 2$, lactate can also predict for successful weaning by adaptive ventilation mode (AVM) in patients with acute exacerbations of COPD.

Keyword: AVM (Adaptive ventilation mode), Exacerbation of COPD, Weaning ventilation.

\section{I. ĐĂT VẤN ĐỀ}

Cai thở máy ở nhóm bênh nhân đợt cấp bênh phổi tắc nghẽn mạn tính( $\mathrm{COPD}$ ) gặp rất nhiều khó khăn dễ gây căng động phổi quá mức, tăng công thở ${ }^{1,2}$. Nếu không lựa chọn phương thức thích hợp, quá trình cai thở máy dễ dẫn đến thất bại làm tăng nguy cơ tử vong, tàn phế và chi phí điều trị cho bênh nhân.

Các phương pháp cai thở máy cho bệnh nhân đợt cấp COPD hiện nay có chung một nhược điểm là mức hỗ trợ không tương xứng với nhu cầu thay đổi liên tục của bệnh nhân, dể dẫn đến mất đồng bộ giữa bệnh nhân và máy thở 3 .

AVM với ưu điểm có khả năng tính toán tự động các thông số cơ học phổi, từ đó đưa ra mức hỗ trợ liên tục và phù hợp với từng tình trạng người bệnh. Đông thời mode thở này cũng giảm thiểu tối đa các thao tác cài đặt cho nhân viên y tế4.

Áp dụng chế độ thông khí thích ứng trong cai thở máy cho bệnh nhân đợt cấp COPD giúp tăng tỷ lê cai máy thở thành công, giảm thời gian nằm viện và giảm chi phís,6. Xác định được các yếu tố tiên lượng thành công khi cai thở máy bằng phương thức $\mathrm{AVM}$ nhằm phát hiện sớm các đối tượng có nguy cơ cần các hỗ trợ thông khí khác.

\section{II. ĐỐl TƯỢNG VÀ PHƯƠNG PHÁP NGHIÊN CỨU}

\section{1 Đối tượng nghiên cứu}

Tiêu chuẩn lựa chon: Các bệnh nhân chẩn đoán đợt cấp COPD đắt ống nội khí quản thở máy trên 24 giờ có đủ tiêu chuẩn cai thở máy.

Tiêu chuẩn loại trừ: Có bệnh lý thần kinh cơ tiến triển, bệnh nhân mở khí quản, bệnh nhân không đồng ý tham gia nghiên cứu.

\subsection{Thời gian địa điểm nghiên cứu:}

Thời gian nghiên cứu: Từ tháng 09/2020 đến tháng 9/2021

Địa điểm nghiên cứu: Trung tâm cấp cứu A9, Bệnh viện Bach Mai.

Thiểt kể nghiên cứu: Nghiên cứu tiến cứu can thiệp

Cỡ mẫu nghiên cứu: Tất cả bệnh nhân nhập viện trung tâm cấp cứu trong thời gian nghiên cứu, phù hợp với tiêu chuẩn lựa chọn, có tất cả 25 bệnh nhân.

Quá trình thu thập số liệu:

- Tiêu chuẩn đánh giá kết quả điều trị:

Thành công: không phải đặt lại nội khí quản sau 48 giờ.

Thất bại: phải đặt lại NKQ hoặc tử vong trong vòng 48 sau rút NKQ.

- Các bước tiến hành nghiên cứu

Đối tượng nghiên cứu vào viện được hỏi tiền sử, bệnh sử, khám lâm sàng để hướng đến chẩn đoán đợt cấp COPD và các dấu hiệu suy hô hấp. 
Các thông số về cận lâm sàng: Công thức máu, máu lắng, $\mathrm{CRP}$, sinh hóa máu cơ bản, khí máu động mạch, chụp phim phổi.

Các thông số theo dõi chính bao gồm: Mạch, huyết áp, nhịp thở, $\mathrm{SpO}_{2}$, khí máu $\left(\mathrm{pH}, \mathrm{PaO}_{2}\right.$, $\left.\mathrm{PaCO}_{2}, \mathrm{HCO}^{-}\right)$, được thu thập tại các thời điểm: nhập viện, bắt đâu cai máy thở bằng $A V M$, sau thở AVM 30 phút, sau 60 phút, sau 120 phút, trước rút ống nội khí quản hoặc trước khi chuyển sang thông khí kiểm soát và sau rút ông nội khí quản.
2.3 Phân tích số liệu: Bằng phần mềm thống kê SPSS phiên bản 20, dữ liệu được trình bày dưới dạng tân số và tỉ lệ phần trăm với biến định tính, dạng trung bình \pm độ lệch chuẩn hoặc trung vị (tứ phân vị) với biến định lượng. So sánh sự khác biệt giữa các nhóm dùng thuật toán Mann - Whitney $U$ test hoặc $T$ test với biển liên tục và Khi bình phương test bới biến phân loại. Khác biệt có ý nghĩa thống kê khi giá trị kiểm định $\mathrm{p}<0.05$.

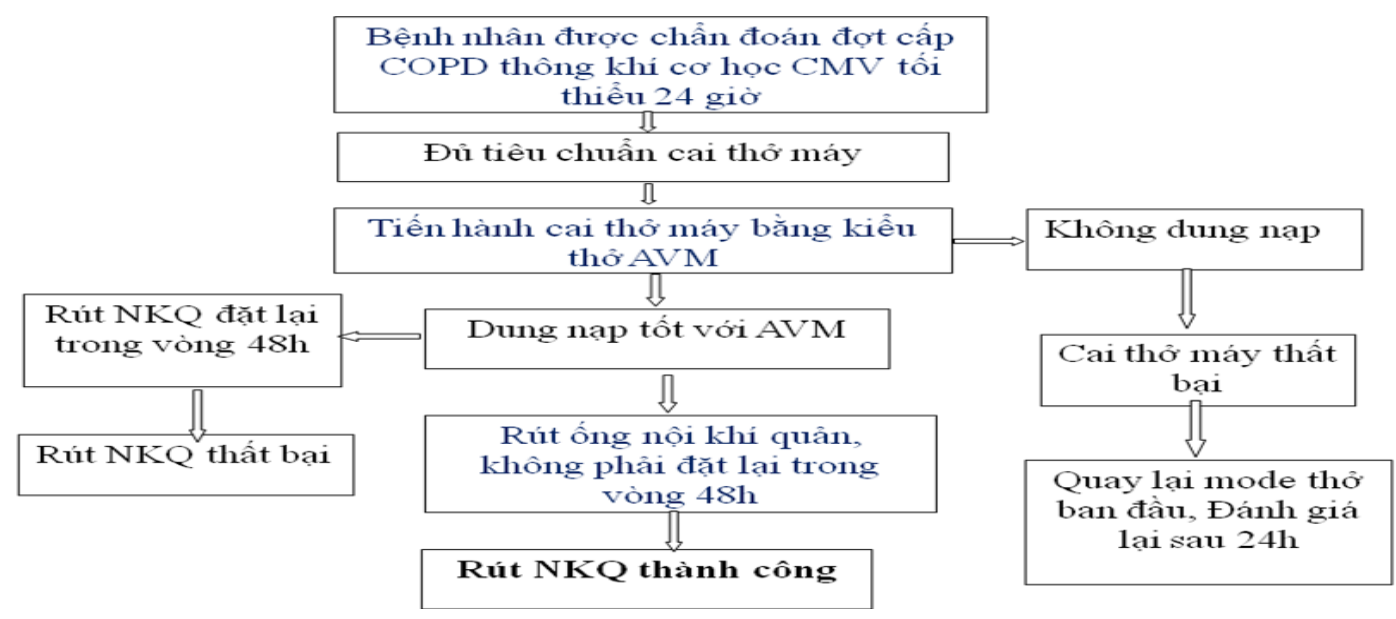

\section{KẾT QUẢ NGHIÊN CỨU}

Có 25 bệnh nhân đủ tiêu chuẩn đưa vào nghiên cứu. Trong đó có 21 bệnh nhân rút nội khí quản thành công (84\%).

\begin{tabular}{|c|c|c|c|c|}
\hline & Tống số( $n=25)$ & Thành công( $(n=21)$ & Thất bại $(n=4)$ & Giá trị p \\
\hline Tuổi & $74(59-91)$ & $75(59-91)$ & $78(73-80)$ & 0,534 \\
\hline Nam, n (\%) & $23(92 \%)$ & $19(90,4 \%)$ & $4(100 \%)$ & 0,640 \\
\hline \multicolumn{5}{|c|}{ Tiền sử hút thuốc và bệnh đồng mắc, $n(\%)$} \\
\hline Hút thuốc lào, thuốc lá & $23(92 \%)$ & $19(90,4 \%)$ & $4(100 \%)$ & 0,640 \\
\hline Tăng huyết áp & $9(36 \%)$ & $7(33,3 \%)$ & $2(50 \%)$ & 0,755 \\
\hline Đái tháo đường & $6(24 \%)$ & $4(19 \%)$ & $2(50 \%)$ & 0,834 \\
\hline Suy tim & $7(28 \%)$ & $4(19 \%)$ & $3(75 \%)$ & 0,657 \\
\hline \multicolumn{5}{|c|}{ Đặc điểm về BMI, SOFA, APACHE II của nhóm bệnh nhân khi nhập viện } \\
\hline BMI & $20,11(14,6-27,6)$ & $20,73(14,6-27,6)$ & $17,48(15,5-20,7)$ & 0,139 \\
\hline SOFA & $5,6(1-11)$ & $4,8(1-8)$ & $9(7-11)$ & 0.002 \\
\hline APACHE II & $17,19(8-25)$ & $16,24(8-24)$ & $21,2(18-25)$ & 0.047 \\
\hline \multicolumn{5}{|c|}{ Kết quả khí máu khi nhập viện } \\
\hline $\mathrm{pH}$ & $7,21(7,11-7,33)$ & $7,20(7,11-7,33)$ & $7,22(7,17-7,32)$ & 0,88 \\
\hline $\mathrm{PaCO} 2$ & $82,8(44-112)$ & $83,5(56-112)$ & $79,5(44-109)$ & 0,82 \\
\hline $\mathrm{PaO} 2$ & $114,5(69-280)$ & $115,2(69-280)$ & $112(93-160)$ & 0,89 \\
\hline HCO3- & $32,2(20-50)$ & $32,5(20-50)$ & $30,5(21-40)$ & 0,72 \\
\hline Lactat & $3,9(0,8-8)$ & $4,3(0,8-8)$ & $2,9(1,3-5,7)$ & 0,32 \\
\hline \multicolumn{5}{|c|}{ Kết quả cai máy } \\
\hline $\begin{array}{c}\text { Thời gian cai thở máy bằng } \\
\text { AVM (giờ) }\end{array}$ & $10,5(3-22)$ & $9(3-19)$ & $16,75(10-22)$ & 0,008 \\
\hline Thời gian nằm ICU (ngày) & $9,05(2-62)$ & $6,29(2-10)$ & $20,75(5-62)$ & 0,032 \\
\hline Thời gian nằm viện (ngày) & $17,86(5-62)$ & $15,53(5-32)$ & $27,75(5-62)$ & 0,125 \\
\hline
\end{tabular}


Nhận xét: Tỷ lệ bệnh nhân COPD có tiền sử hút thuốc lào, thuốc lá là rất cao, chiếm đa số bệnh nhân trong nhóm nghiên cứu.Các tiền sử bểnh lý thường gặp là: tăng huyết áp, suy tim, đái tháo đường. Không có sự khác biệt giữa 2 nhóm về tiền sử hút thuốc và các bệnh đồng mắc.

Nhóm nghiên cứu có điểm SOFA và điểm APACHE II ở mức trung bình. Nhóm cai máy thất bại có điểm SOFA và $A P A C H E$ cao hơn nhóm thành công với $p<0,05$. Đa phần bệnh nhân có BMI thấp, không có sự khác biết giữa 2 nhóm.

Khí máu lúc nhập viện thể hiện tình trạng toan hô hấp cấp, tăng $\mathrm{CO}_{2}$ máu và giảm oxy máu. Chỉ số lactat và $\mathrm{HCO}_{3}{ }^{-}$đều cao hơn mức bình thường. Giữa 2 nhóm thành công và thất bại các chỉ số khí máu tại thời điểm nhập viện không có sự khác biệt.

Nhóm cai thở máy thất bại có thời gian cai thở máy và thời gian nằm ICUं cao hơn nhiều so với nhóm cai thở máy thành công với khác biệt có ý nghĩa $p<0,05$. Thời gian nằm viện cao hớn ở nhóm thất bại .

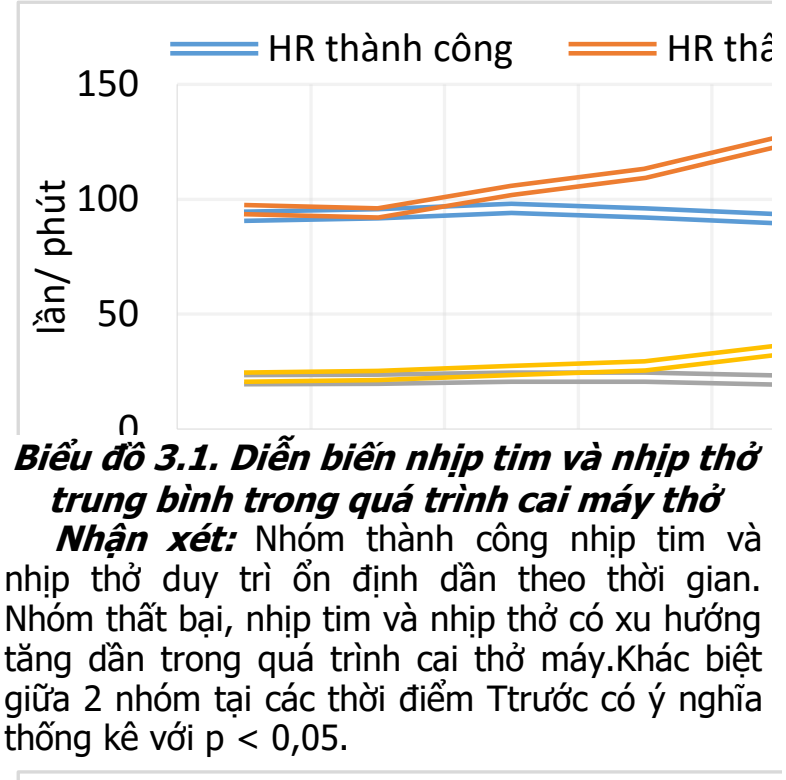

7.50

7.40

7.30

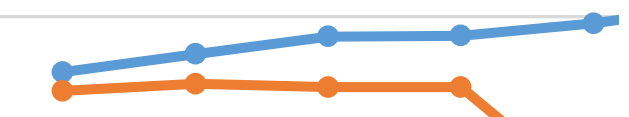

Thành công Thất b:

Biểu đồ 3.2. Diễn biến pH trong quá trình

\section{cai máy thở}

Nhận xét: Nhóm thành công, pH có xu hướng tăng lên và ổn định dân trong suốt quá trình cai thở máy. Nhóm thất bại có $\mathrm{pH}$ giảm dần cho đến thời điểm quay lại mode thở ban đầu.Tại thời điểm Ttruoc, khác biệt pH có ý nghĩa thống kê giữa 2 nhóm với $p<0,05$.

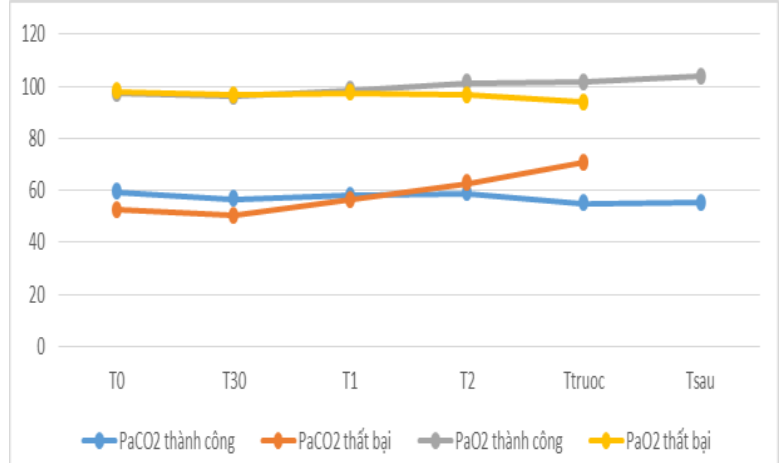

Biểu đồ 3.3. Diễn biến PaO2 và PaCO2 trong quá trinh cai máy thở

Nhận xét: $\mathrm{PaO}_{2}$ của cả hai nhóm trong quá trình cai thở máy ổn định, sự khác biệt không có ý nghĩa thống kê tại các thời điểm nghiên cứu $\mathrm{p}>0.05$. Nhóm thành công, $\mathrm{PaCO}_{2}$ ổn định dần trong quá trình cai thở máy cho đến lúc rút ống nội khí quản thành công. Nhóm thất bại, $\mathrm{PaCO}_{2}$ tắng dần cho đến thời điểm Ttruoc và tại thời này $\mathrm{PaCO} 2$ khác biệt giữa 2 nhóm có ý nghĩa thống kê $p<0,05$.

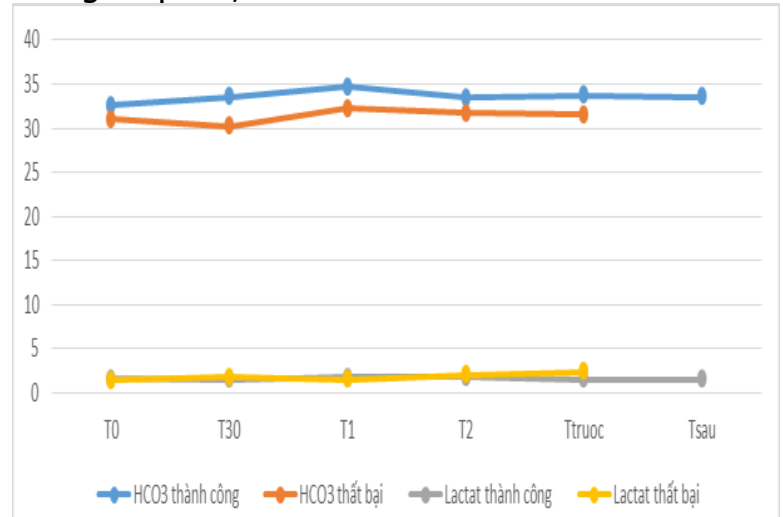

Biểu đồ 3.4. Diễn biến HCO3 và lactat trong quá trinh cai máy thở

Nhân xét: Cả hai nhóm chỉ số $\mathrm{HCO} 3$ máu tại các thời điểm cai thở máy không có sự khác biệt mang ý nghĩa thống kê và duy trì ổn định trong suốt quá trình cai thở máy. Chỉ số lactat của nhóm thành công duy trì ổn định theo thời gian trong quá trình cai thở máy, của nhóm thất bại tăng dân, khác biệt giữa 2 nhóm tại thời điểm Ttruoc có ý nghĩa thống kê với $p<0,05$. 


\section{BÀN LUẬN}

Độ tuổi trung bình của nhóm bệnh nhân nghiển cứu của chúng tôi là $74,04 \pm 9,92$ tuổi. Tỷ lệ bệnh nhân nam (92\%) gặp nhiều hơn nữ (8\%). Không có sự khác biết về tuổi và giới giữa 2 nhóm, tương đương với nghiên cứu của tác giả Shin và cộng sự7, khác với kết quả của tác giả Savi và cộng sựi , tỷ lệ nhóm thất bại cao hơn ở đối tượng bệnh nhân trên 65 tuổi sự khác biệt này có thể do khác nhau về nhóm đối tượng bệnh nhân cai thở máy.

Khi tiến hành cai thở máy bằng phương thức thông khí AVM, chúng tôi ghi nhận 21 trường hợp cai thở máy thành công, chiếm $84 \%$, cao hơn của tác giả Kirakli và cộng sự $71.4 \%$, trong số 21 trường hợp này không có bệnh nhân nào phải đặt lại ống nội khí quản trong vòng 48 giờ. Kết quả này cho thãy phương thức thông khí có tỷ lệ cai thở máy và rút ông nội khí quản thành công cao ở bệnh nhân COPD có thông khí cơ học.

Khí máu khi nhập viện của nhóm bệnh nhân nghiên cứu thể hiện tình trạng toan hổ hấp cấp $(\mathrm{pH} 7,21 \pm 0,07)$, tăng $\mathrm{CO}_{2}$ máu $\left(\mathrm{PaCO}_{2}\right.$ $82,8 \pm 20,4 \mathrm{mmHg})$, điều này phù hợp với tính chất của đợt mất bù cấp COPD. Oxy máu trung bình trong giới hạn cho phép $(114,5 \pm 59,6$ $\mathrm{mmHg}$ ), chỉ có 3 bệnh nhân có mức $\mathrm{PaO}_{2}$ dưới $80 \mathrm{mmHg}$. Chỉ số $\mathrm{HCO}_{3}{ }^{-}$tăng $(32,2 \pm 7,4 \mathrm{mmHg})$, thể hiện tình trạng tăng $\mathrm{CO}_{2}$ mạn tính trong nhiều năm, là đặc điểm đặc trưng của bệnh lý COPD. Chỉ số lactat tăng $(3,9 \pm 1,9 \mathrm{mmol} / \mathrm{l})$ ở những bệnh nhân COPD có thể do quá trình vận động nhẹ nhàng cũng dễ gây tăng lactat hoặc do thiếu ô xy gây nên. Không có sự khác biệt giữa 2 nhóm về các thông số khí máu khi nhập viện.

Nhóm cai máy thất bại có điểm SOFA và APACHE tại thời điểm nhập viện cao hơn nhóm thành công với $p<0.05$. Chúng tôi nhận thấy mức độ nặng của bệnh nhân khi ảnh hưởng có ảnh hưởng đến kết quả cai thở máy, điểm APACHE II là một trong các thông số có ý nghĩa trong dự đoán kết quả cai thở máy thành công. John và cộng sự (2012) ${ }^{9}$ đưa ra một số yếu tố nguy cơ cai thở máy thất bại, trong đó có tuổi $\geq$ 65 tuổi và điểm $A P A C H E>12$. Kết quả này tương đương với kết quả của tác giả Shin và cộng sự 7 .

Diễn biến các thông số lâm sàng: nhịp tim, nhịp thở, huyết áp trung bình, SPO2, và khí máu: $\mathrm{pH}, \mathrm{PaO} 2, \mathrm{PaCO} 2, \mathrm{HCO} 3$, lactat của nhóm thành công duy trì ổn định trong quá trình cai máy đến khi rút ông nội khí quản, nhóm thất bại có nhịp tim, nhịp thở, lactat, $\mathrm{PaCO} 2$ tăng dần, và $\mathrm{pH}$ giảm dần trong quá trình cai máy sự khác biệt khác biệt có ý nghĩa tại thời điểm trước khi rút nội khí quản hoặc chuyển lại chế độ thở kiểm soát với $\mathrm{p}<0.05$. Kết quả của chúng tôi tương đồng với kết quả của tác giả Savi và cộng sự không có sự khác biệt giữa 2 nhóm vào thời điểm bắt đầu cai máy thở về $\mathrm{pH}, \mathrm{PaCO} 2, \mathrm{PaO} 2$, nhịp tim, nhịp thở. Tại thời điểm sau cai máy 30 phút, $\mathrm{PaO} 2$ giảm, tần số thở tăng ở nhóm thất bại vơi $p<0,05$. Trong nghiên cứu của Mabrouk và cộng sự , có sự khác biệt giữa 2 nhóm về $\mathrm{pH}$, $\mathrm{PaO} 2$ và $\mathrm{PaCO} 2$ với $\mathrm{p}<0,05$.

\section{KẾT LUÂ̂N}

Thang điểm APACHE II, SOFA tại thời điểm nhập viện có khả năng dự báo kết quả rút ống nội khí quản thành công. Theo dõi diễn biến trong quá trình cai máy về nhịp tim, nhịp thở, $\mathrm{pH}, \mathrm{PaCO} 2$, lactat có thể tiên lượng cai máy thở thành công áp dụng phương thức thông khí thích ứng cho bệnh nhân đợt cấp COPD.

\section{TÀI LIỆU THAM KHẢO}

1. Barnes PJ. Immunology of asthma and chronic obstructive pulmonary disease. Nat Rev Immunol. 2008;8(3):183-192.

2. Kacmarek RM, Stoller JK, Heuer A. Egan's Fundamentals of Respiratory Care-E-Book. Elsevier Health Sciences; 2016.

3. Nguyễn Đạt Anh (2009). Những Vấn Đê Cơ Bản Trong Thông Khí Nhân Tạo Bản Dịch Tiếng Việt. Nhà Xuất Bản Y Học, Hà Nội.

4. Brunner JX, Iotti GA. Adaptive Support Ventilation (ASV). MINERVA Anestesiol. 2002;68(5):5.

5. Kirakli C, Ozdemir I, Ucar ZZ, Cimen P, Kepil S, Ozkan SA. Adaptive support ventilation for faster weaning in COPD: a randomised controlled trial. Eur Respir J. 2011;38(4):774-780. doi:10.1183/09031936.00081510

6. Mohamed KAE, kamal El Maraghi S. Role of adaptive support ventilation in weaning of COPD patients. Egypt J Chest Dis Tuberc. 2014;63(2):449-454.

7. Shin H-J, Chang J-S, Ahn S, et al. Clinical factors associated with weaning failure in patients requiring prolonged mechanical ventilation. J Thorac Dis. 2017;9(1):143-150. doi:10.21037/ jtd.2017.01.14

8. Savi A, Teixeira C, Silva JM, et al. Weaning predictors do not predict extubation failure in simple-to-wean patients. J Crit Care. 2012;27(2):221.e1-221.e8. doi:10.1016/j.jcrc.2011.07.079

9. McConville J. F. , P. K. J. (2012). Weaning Patients from the Ventilator. N Engl J Med, 367 (23), 2233-2239. 